\title{
Respostas Magnéticas e Radiométricas da Sequência Anicuns-Itaberaí, Complexo Anápolis-Itauçu, Intrusões Félsicas e Máfico-Ultramáficas da região de Anicuns, Goiás
}

Lara Maciel Feitosa*, Marco Tulio Guimarães*, Silvencler Batista Bezerra*, Marcelo Henrique Leão-Santos*, Rodrigo Prudente de Melo, UNIVERSIDADE FEDERAL DE GOIÁS, FACULDADE DE CIÊNCIAS E TECNOLOGIA, Brasil

Copyright 2021, SBGf - Sociedade Brasileira de Geofísica

This paper was prepared for presentation during the $17^{\text {th }}$ International Congress of the Brazilian Geophysical Society held in Rio de Janeiro, Brazil, 16-19 August 2021.

Contents of this paper were reviewed by the Technical Committee of the $17^{\text {th }}$ International Congress of the Brazilian Geophysical Society and do not necessarily represent any position of the SBGf, its officers or members. Electronic reproduction or storage of any part of this paper for commercial purposes without the written consent of the Brazilian Geophysical Society is prohibited.

\section{Abstract}

This work is focused on magnetic and radiometric data processing and geological interpretation, from Anicuns, Goiás region. The study area is located in Itaberaí (SE.22X-A-III) and Sanclerlândia (SE.22-X-A-II) geological maps with 1:100.000 scale.

The results of the research allow the inference of geological structures, kinematic indicators, allocation of magnetic and radiometric domains correlated with geological units and a better understanding of the region's tectonic framework. The main purpose is to create a lithogeophysical map to be checked in field camp to improve the literature and geology cartography to give support for locating mineral resources in the future.

The production of the maps was performed with data processing, applying methods such as quality control, 2-D interpolation and transformation of the data that generated several products: Total Gradient, Vertical Derivative, Total Horizontal Gradient (magnetic data) and images of $\mathrm{K}, \mathrm{U}$ and Th channels, Total Count and RGB - K Th U Ternary Image (radiometric data).

The results of magnetic data interpretation allow the delimitation of high magnetic structures and domains. The radiometric data interpretation allows the delimitation of domains correlated with the main geological units. The correlation with the geological information of the region generate final products, which contribute to the previous knowledge of Metavolcanosedimentary Sequence Anicuns-Itaberaí, Anápolis-Itauçu Granulite Complex, Felsic and Mafic-Ultramafic Intrusions, and understanding of the relations of the anomalies with the local geology.

\section{Introdução}

O reprocessamento de dados aerogeofísicos de um levantamento, são cruciais para empregá-los em áreas de interesse, principalmente para mapeamento geológico. 0 principal ganho em relação aos produtos regionais, é a redefinição das escalas de cores, gradiente e um melhor processamento na retirada de tendências locais nos novos grids interpolados. Estas tendências não são observáveis em escalas regionais do levantamento como um todo. A interpretação geofísica é uma ferramenta rápida e relativamente barata que pode ser utilizada em mapeamento geológicos, para auxiliar na obtenção de informações geotectônicas e de potencial mineral de uma área.

A área de estudo se situa na região entre Americano do Brasil e Anicuns, em Goiás, e é compreendida pela porção centro-sul do Levantamento Aerogeofísico do Estado de Goiás - 1a Etapa: Arco Magmático de Arenópolis (CPRM/LASA, 2004) conforme indica a figura 1. O objetivo principal do trabalho é o processamento e a interpretação de dados geofísicos obtidos na região, para dar suporte ao mapeamento geológico de escala 1:50.000 a ser realizado na região. Os resultados do processamento e interpretação dos dados são relevantes para a melhor compressão da resposta geofísica da região de forma a aumentar a qualidade dos mapas locais e fornecer dados complementares aos mapeamentos geológicos.

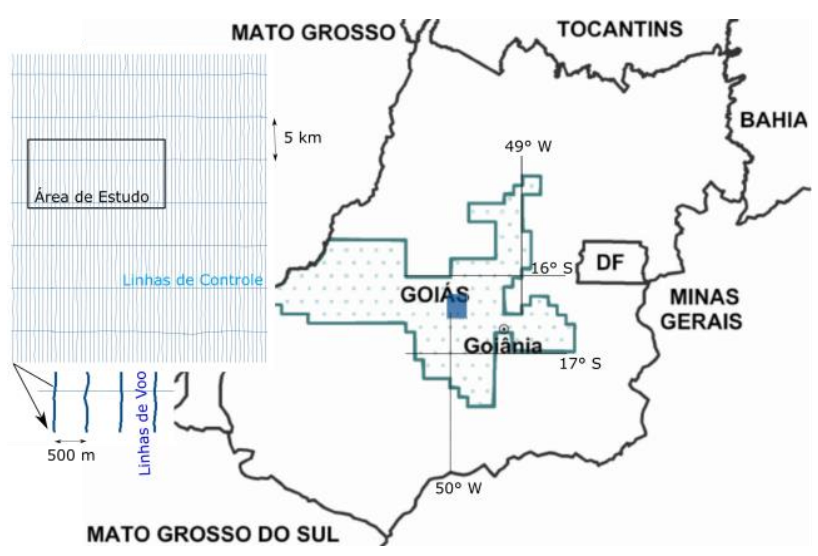

Figura 1 - Localização do Levantamento Aerogeofísico de Goiás utilizado e da área de estudo, bem como disposição das linhas de aquisição de dados.

\section{Método}

Processamento e Interpretação dos dados

A princípio foi necessária a conversão do DATUM dos dados aerogeofísicos para SIRGAS 2000, visto que os dados do aerolevantamento foram obtidos no período em que o DATUM SAD 69 estava em vigor. A partir disso, realizou-se o controle de qualidade que consiste na análise da distribuição de dados, de desvios nas especificações técnicas do levantamento (espaçamento de $0,5 \mathrm{~km}$ das linhas de voo; 5,0 km das linhas de controle, e altura de voo a $100 \mathrm{~m}$ ) e de inconsistência nos dados com uso da derivada de $4^{a}$ ordem (efeitos pepita, spikes, valores gamaespectrométricos negativos etc.). Algumas linhas de voo tiveram eventuais desvios, mas o padrão geral das mesmas não apresentou maiores problemas, 
RESPOSTAS GEOFÍSICAS NA REGIÃO DE ANICUNS, GOIÁS

fato também observado quanto às variações de altitudes barométricas. No geral os dados não apresentaram inconsistências significativas.

No que tange ao processamento dos dados aerogeofísicos, anteriormente à escolha do método de interpolação, é importante definir a dimensão da célula de interpolação. Neste trabalho a dimensão ideal da célula de interpolação foi tida como 100 m, 1/5 do espaçamento das linhas de voo. Posteriormente à definição do tamanho da célula, foram analisadas as opções de métodos de interpolação, devidamente aplicados levando em consideração tanto a fidelidade dos perfis com o dado original, como por comparação visual. Após os testes de eficácia de interpolação, o método de interpolação escolhido para o processamento dos dados gamaespectrométricos foi a curvatura mínima, e para os dados magnetométricos o método de splines bi-cúbicos (Bi-Direcional).

Sobre os dados magnetométricos interpolados foi necessário o uso do filtro de convolução $5 \times 5$ aplicado 2 vezes para melhor apresentação dos dados. Enquanto nos dados gamaespectrométricos utilizou-se 0 filtro de convolução $5 \times 5$ aplicado 5 vezes. Como etapa final os dados magnetométricos e gamaespectrométricos interpolados foram exportados para interpretação em ambiente de sistema de informações georreferenciadas (SIG), para melhor análise de domínios geofísicos. Para correlação entre os diversos produtos geofísicos e geológicos foram produzidos isocontornos de intensidade magnética e contagem gamaespectrométrica para diferentes intervalos.

No SIG, foram dispostas as imagens, importados os isocontornos, e, em seguida, interpretados os lineamentos e domínios geofísicos. Para correlação geofísicageológica foi utilizada a técnica de superposição de imagens (draping of images) dos produtos geofísicos associados aos dados geológicos da CPRM, disponibilizados nos portais online GEOSGB e SIEG-GO, e literatura geológica da região.

\section{Resultados}

\section{Interpretação Gamaespectrométrica}

A proporção relativa de $\mathrm{K}, \mathrm{U}$ e Th, obtida pela quantificação dos raios gama emitidos pelos isótopos desses elementos, é muito útil na delimitação litológica rasa. Apesar da ampla quantidade de ambiguidades geológicas para uma mesma combinação desses elementos, a utilidade desse método se alcança com auxílio do conhecimento geológico da região estudada. Com o uso das linhas de contorno para cada canal dos radioisótopos supracitados, foi possível delimitar domínios com variadas proporções para K, U e Th, e correlacionar com as unidades já mapeadas e geologia regional (Figura 2). As atribuições qualitativas, baixo, médio e alto, nessa ordem, foram estabelecidas da seguinte forma: $\mathrm{K}$ (< $0,24 \%$; > 0,24\% e < 0,78\%; > 0,78\%), Th $(<4,25 \mathrm{ppm} ;>$ 4,25 e < 9 ppm; > 9 ppm) e U $(<0,34$ ppm; > 0,34 e < 1 ppm; > 1 ppm).
Definidos estes parâmetros quantitativos para interpretação, os domínios finais foram obtidos por intersecção geométrica dos polígonos de baixo, médio e alto de cada canal gamaespectrométrico, de forma que os contornos de $\mathrm{K}$ e Th são mais consistentes e definem os domínios, e o U, mais ruidoso, confere caráter irregular e por vezes variáveis dentro de um mesmo domínio. Os domínios gamaespectrométricos são:

Domínio Gamaespectrométrico I: Apresenta distribuição disseminada no centro e centro norte (geometria elíptica) a leste (corpos alongados NW-SE, irregulares) da área. E caracterizado por possuir alto potássio, alto tório e de baixo a médio urânio. Quando comparado a geologia regional o domínio está associado ao Granito Lage, de litologia composta por minerais com alto teor de potássio, predomínio de K-feldspato, além de biotita. O tório e urânio vem de minerais acessórios nessas rochas como zircão. Sendo que mais a sudeste da área encontra-se relacionado a paragranulitos do Complexo Anápolis-Itauçu (anatexia?).

Domínio Gamaespectrométrico II: Ocorre na porção centro sudoeste da área (geometria irregular alongada NW-SE). Este domínio é caracterizado por possuir alto potássio, baixo tório e urânio. Os parâmetros deste domínio o correlacionam, na geologia regional, a Sequência Metavulcanossedimentar Anicuns-Itaberai (SMVS-AI), unidades psamo-pelíticas. Devido sua assinatura de potássio distinta em relação a Th e U, está relacionado aos mica xistos desta unidade. Ocorre ainda no extremo oeste, relacionado ao Metagranito Sanclerlândia.

Domínio Gamaespectrométrico III: Concentra-se mais na porção central (geometria alongada NE-SW e irregular NS) e ocorre de forma disseminada (geometria irregular) ao leste da área, por vezes alongado na direção NW-SE. Este domínio caracteriza-se por alto potássio, médio tório e urânio variável. Geologicamente, os domínios centro-sul e noroeste se correlacionam a unidades pelito-psamíticas da SMVS-Al devido a valores de Th e U maiores que no Domínio II. O domínio centro norte alongado NW-SE se correlaciona a uma fácies do domínio I com menor anomalia de K. A leste da área, observa-se associação com o domínio I (borda dos corpos) podendo indicar um faciologia granítica em contexto anatético (conforme domínio I na porção leste da área de estudo).

Domínio Gamaespectrométrico IV: Apresenta distribuição disseminada de leste a noroeste da área, com geometria irregular amebóide, alongada em geral NW-SE (N-S no extremo oeste). O domínio possui baixo potássio, alto tório e médio a alto urânio. Geologicamente está associado aos orto- e paragranulitos, possivelmente rochas juvenis com baixo $\mathrm{K}$ e possivelmente feldspatos de $\mathrm{Ca}-\mathrm{Na}$ (evoluídas suficiente para elevar concentração de Th e U) do Complexo Anápolis-Itauçu na porção leste e às coberturas detrito lateríticas ferruginosas a oeste.

Domínio Gamaespectrométrico $\mathrm{V}$ : Abrange parte significativa da porção sudoeste (geometria elíptica a alongada $\mathrm{N}-\mathrm{S}$ ) da área e estende pontualmente para noroeste e nordeste. Caracteriza-se por baixo potássio, baixo tório e baixo a médio urânio. Este domínio está 
FEITOSA, GUIMARÃES, BEZERRA, LEÃO-SANTOS, MELO

geologicamente relacionado a Unidade Básica-Ultrabásica da SMVS-AI quando corpos alongados (premissa de deformação da SMVS-AI), Suíte Gabro-Anortosítica Anicuns-Santa Bárbara, a sudoeste, e Corpo Capelinha do Gomes no extremo nordeste (geometria elíptica).

Domínio Gamaespectrométrico VI: Ocorre de forma disseminada (geometria irregular) por toda a área, em arco de leste, centro-norte a oeste. Este domínio é caracterizado por baixo potássio, médio tório e urânio variando. Geologicamente encontra-se associado aos ortogranulitos do Complexo Anápolis-Itauçu, a leste da área e às coberturas detrito lateríticas ferruginosas nos demais porções. Nota-se relação com os domínios IV e V: sendo que, juntamente com o domínio IV define delimitações de ortogranulitos a leste e coberturas detritolateríticas a oeste, e quando associado com o domínio V pode indicar a continuidade das rochas básicasultrabásicas no sudoeste-oeste e extremo nordeste da área.

Domínio Gamaespectrométrico VII: Abrange a porção leste da área (elíptica NW-SE) e mais disseminada a noroeste. Define-se por médio potássio, alto tório e médio a alto urânio. Quando comparado a geologia regional o domínio está associado a Unidade paragranulitica do Complexo Anápolis-Itauçu (leste), psamitos-ritmitos carbonatados da SMVS-AI.

Domínio Gamaespectrométrico VIII: Ocorre na porção sudoeste da área (geometria irregular alongada NNWSSE). Representa médio potássio, baixo tório e baixo a médio urânio. Geologicamente relacionado às Unidades Psamo-pelítica e Básico-ultrabásica da Sequência Metavulcanossedimentar Anicuns-Itaberaí, e por vezes ao Metagranito Sanclerlândia. Apresenta grande ambiguidade, sendo correlacionável tanto a psamitos da SMVS-AI como possíveis alterações hidrotermais de larga escala nas rochas básicas-ultrabásica.

Domínio Gamaespectrométrico IX: Trata-se do domínio que abrange maior parte da área, distribuído por várias porções, mas se destaca na parte central estendendo para porção norte-noroeste. Caracterizado por médio potássio, médio tório e médio a alto urânio. É o domínio mais ambíguo e perfaz diversos contextos que só o trabalho em campo pode elucidar.

\section{Interpretação Magnetométrica}

Os produtos magnetométricos foram incorporados no SIG para interpretação geofísica das estruturas e domínios magnéticos e correlação com a cartografia geológica disponível (Figura 3).

O Gradiente Total foi utilizado para delinear as bordas das fontes magnéticas, com menor dependência do vetor de magnetização, atrelado aos seus isocontornos (intervalos de: baixa intensidade magnética $<0,034 \mathrm{nT} / \mathrm{m}$, média intensidade magnética 0,034 a $0,136 \mathrm{nT} / \mathrm{m}$, e alta intensidade magnética $>0,136 \mathrm{nT} / \mathrm{m})$. Os intervalos serviram de base para delimitação dos domínios magnéticos, com refinamento assistido pela Derivada Vertical para melhor delimitação das fontes rasas das anomalias magnéticas e o Gradiente Horizontal Total para a demarcação dos domínios magnéticos por conferir vantagem na delimitação dos limites laterais das anomalias. As estruturas por sua vez são um compilado de informações de feições obtidas em todos os mapas magnéticos, mas foram validadas pela Inclinação do Sinal Analítico. A Inclinação do Sinal Analítico foi bastante útil na categorização de domínios magnéticos estruturados, que podem indicar uma prévia das relações tectônicas entre domínios geológico-geofísicos deformados.

De acordo com a figura 4, observa-se um grande domínio central de variável intensidade magnética (média a baixa) e intensa estruturação, envelopado por duas feições lineares NW-SE indicativas de rochas/estruturas magnéticas de $1^{\underline{a}}$ ordem. Na porção SW e NE da área de estudo foram definidos domínios e estruturas magnéticas de alta e média intensidades respectivamente, que contém feições elípticas.

Segundo os dados geológicos da CPRM em Meneghini (2020), de forma geral os domínios centrais são ambíguos na tentativa de diferenciar rochas da Sequência Metavulcanossedimentar Anicuns-Itaberaí das pertencentes ao Complexo Granulítico Anápolis-Itauçu. Entretanto, podemos observar um domínio de baixo magnético no noroeste da área relacionado a Unidade Psamo-pelítica seguido logo a leste por um domínio mais magnético associado a Unidade Básico-Ultrabásica, ambos da Sequência Anicuns-Itaberaí. Na parte centrooeste a leste da área, correlacionada ao Complexo Anápolis-Itauçu, observamos uma tendência de anomalias mais intermediárias a baixas com uma porção central mais magnética, talvez associada a uma zona de falha.

Os dois grandes domínios lineares de alta intensidade magnética de $1^{\text {a }}$ ordem e direção NW-SE devem estar associados a diques magnéticos de proporções regionais não aflorantes e, portanto, não mapeados na cartografia geológica da região.

O domínio de alta intensidade magnética da SW está correlacionado a Suíte Anicuns-Santa Bárbara associada a presença de magnetita nas rochas máfico-ultramáficas. O domínio de média intensidade a NE está correlacionado aos metanoritos e gabros magnéticos da Suíte MáficoUltramáfica Taquaral-Trindade - Corpo Capelinha dos Gomes.

A estruturação geral é marcada por lineamentos E-W de $2^{\text {a }}$ ordem, que aparentam seccionar lineamentos de $1^{\text {a }}$ a $2^{\text {a }}$ ordem aproximadamente N-S. Em correlação com os dados estruturais de Meneghini (2020), as feições N-S representam o eixo de empurrão e empilhamento tectônico das unidades, e as feições E-W podem indicar a tectônica tangencial cisalhante de alto ângulo de mergulho quando da acomodação da deformação, incluindo aspectos sigmoidais e break'n seal.

A comparação com os dados estruturais da base de dados da CPRM em Meneghini (2020), indica que os domínios lineares de maior intensidade magnética de orientação NW-SE indicam feições/corpos tardi- a pósdeformacionais que cortam toda a estruturação tectônica da área. Entretanto, na feição mais a SW, pode-se observar que as estruturas NE-SW claramente 
RESPOSTAS GEOFÍSICAS NA REGIÃO DE ANICUNS, GOIÁS

observadas na Inclinação do Sinal Analítico, cortam a feição e indicam terminações de zonas de cisalhamento sinistral ou estes lineamentos com tendência E-W de $2^{\mathrm{a}}$ ordem que infletem de forma a envelopar o Corpo Córrego Seco e são resposta da intrusão tardi- a pós-tectônica desta Suíte Máfico-Ultramáfica.

\section{Conclusões}

A interpretação dos mapas magnéticos e gamaespectrométricos permitiu a delimitação regional de unidades geológicas e elementos estruturais, por meio de domínios, lineamentos e anomalias características. A validade dos esboços delimitados, entretanto, exige verificação de campo, ainda mais relevante devido às discrepâncias parciais com a literatura da região.

Pode-se notar que os métodos de interpolação 2-D mostraram resultados diferentes, o método bidirecional foi utilizado no processamento dos dados magnéticos com poucas perdas de dados e se confirmou como um ótimo método interpolador para linhas de aquisição paralelas. No entanto na interpolação dos dados gamaespectrométricos provou-se superior o método de curvatura mínima devido a maior agilidade no processamento dos dados.

O Gradiente Total associado aos produtos de Derivada Vertical e Gradiente Horizontal Total aplicados aos dados magnéticos se mostraram eficientes na delimitação de estruturas e domínios magnéticos. Foram estabelecidos os principais lineamentos relacionados às falhas de empurrão e empilhamento tectônico das unidades, as estruturas $E-W$ de $2^{\text {a }}$ ordem, que seccionam estruturas de $1^{\text {a }}$ a $2^{\text {a }}$ ordem N-S, e estruturas tardi- a pós-tectônicas das intrusões básicas, félsicas e máficas-ultramáficas. Os domínios magnéticos diferenciam as unidades internas da Sequência Anicuns-Itaberaí, o Complexo Anápolis-Itauçu, as Suítes máfico-ultramáficas e os diques magnéticos tardios interpretados.

Já as imagens geradas pelos espectros de potássio, urânio e tório, permitiram a delimitação de diversos domínios gamaespectrométricos com correlações geológicas de suas assinaturas características. Foi possível diferenciar as Unidades Psamo-pelítica, Básicaultrabásica e Rítmica-carbonatada, da Sequência Metavulcanosssedimentar Anicuns-Itaberaí, o Complexo Anápolis-Itauçu, as intrusões félsicas do Granito Laje, as Suítes Máfico-Ultramáficas Anicuns-Santa Bárbara (Corpo Córrego Seco) e Taquaral-Trindade (Corpo Capelinha dos Gomes).

As correlações geológicas com os produtos interpretados magnéticos e gamaespectrométricos permitiram a inferência de estruturas com suas respectivas cinemáticas, delimitação de domínios em unidades geológicas e melhor compreensão do sistema tectônico da região.

O trabalho, portanto, permitiu a avaliação da qualidade de levantamentos, aplicação de métodos/técnicas de processamento de dados e desenvolvimento de bagagem interpretativa de respostas geofísicas com demarcação de estruturas anômalas, delimitação de domínios e correlações geológicas em mapas litogeofísicos. Além disso, os dados obtidos contribuem para o maior conhecimento prévio das áreas de estudo dos mapeamentos a serem realizados na região de forma a gerar pontos de interesse e melhorar o planejamento prévio do trabalho de campo.

\section{Agradecimentos}

Ao Serviço Geológico do Brasil (CPRM) e ao governo de Goiás, pela cessão e permissão do uso dos dados dos levantamentos aerogeofísicos.

\section{Referências}

CPRM - Serviço Geológico do Brasil / Lasa Engenharia e Prospecções, 2004. Levantamento aerogeofísico do estado de Goiás - 1aㅡ etapa: Arco Magmático de Arenópolis, Complexo Anápolis-Itauçu, Sequência VulcanoSedimentar de Juscelândia, relatório final do levantamento e processamento dos dados magnetométricos e gamaespectrométricos. Rio de Janeiro. $22 \mathrm{v}$.

Meneghini, Paulo Fernando Villas Boas; Carneiro, Jonatas de Sales Macedo, 2020. Carta Geológica, Folha Itaberaí. Escala 1:100.000. CPRM Serviço Geológico do Brasil. Programa Novas Fronteiras - Levantamento Geológico e Potencial de Novas Fronteiras. Projeto Oeste de Goiás. Mapa col. Goiânia.
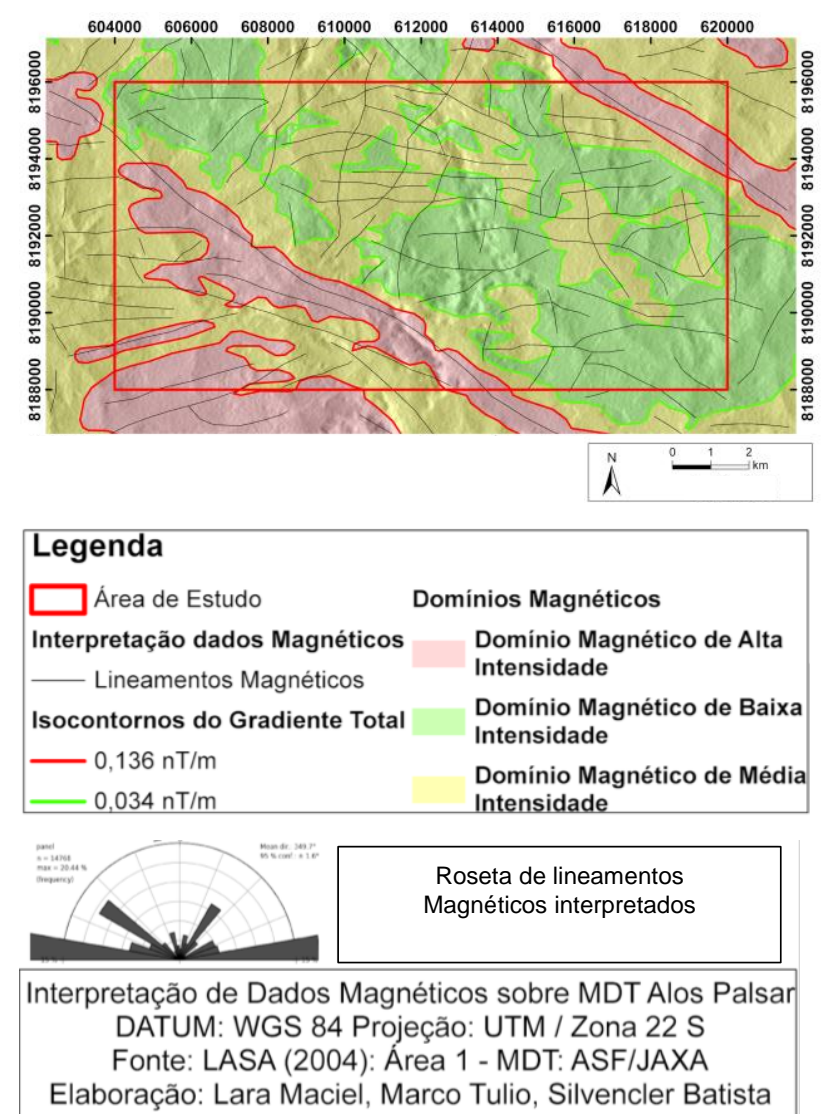

Figura 4 - Domínios e lineamentos magnéticos interpretados. 
FEITOSA, GUIMARÃES, BEZERRA, LEÃO-SANTOS, MELO
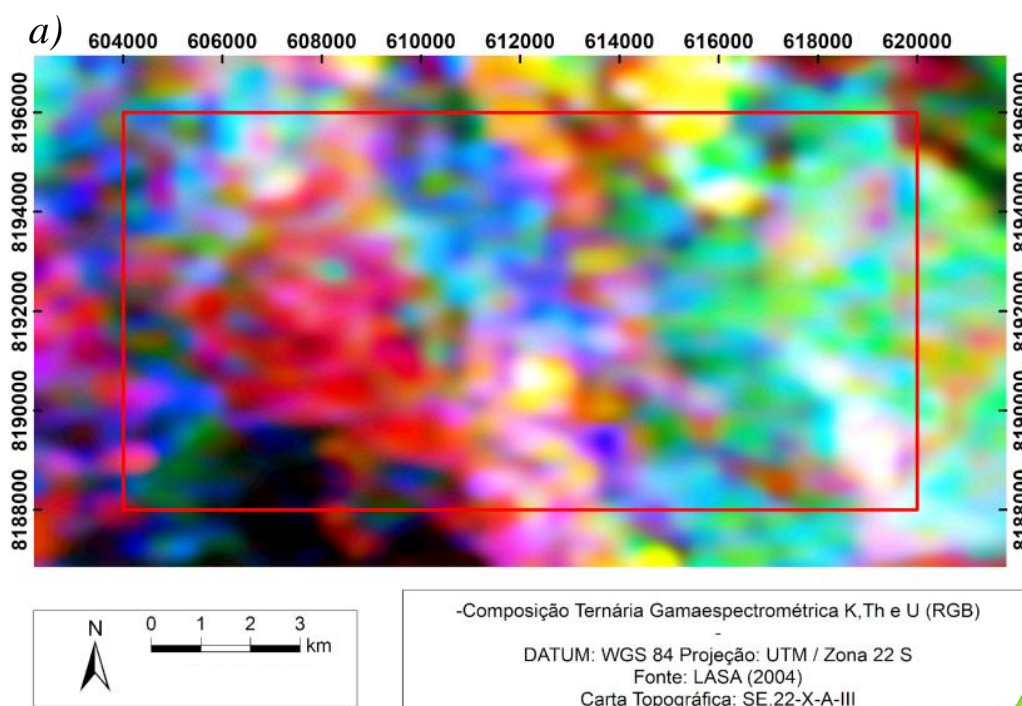

, DATUM: WGS 84 Projeção: UTM / Zona $22 \mathrm{~S}$ Carta Topográfica: SE .22-X-A-A b)

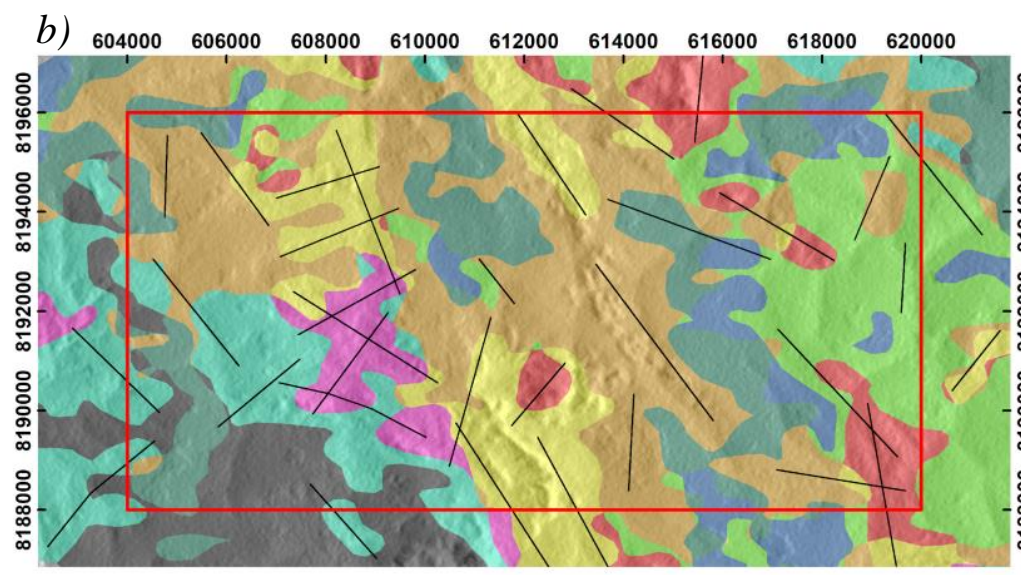
Elaboração: Larta Topográfica: SE.22-X-A-IIII

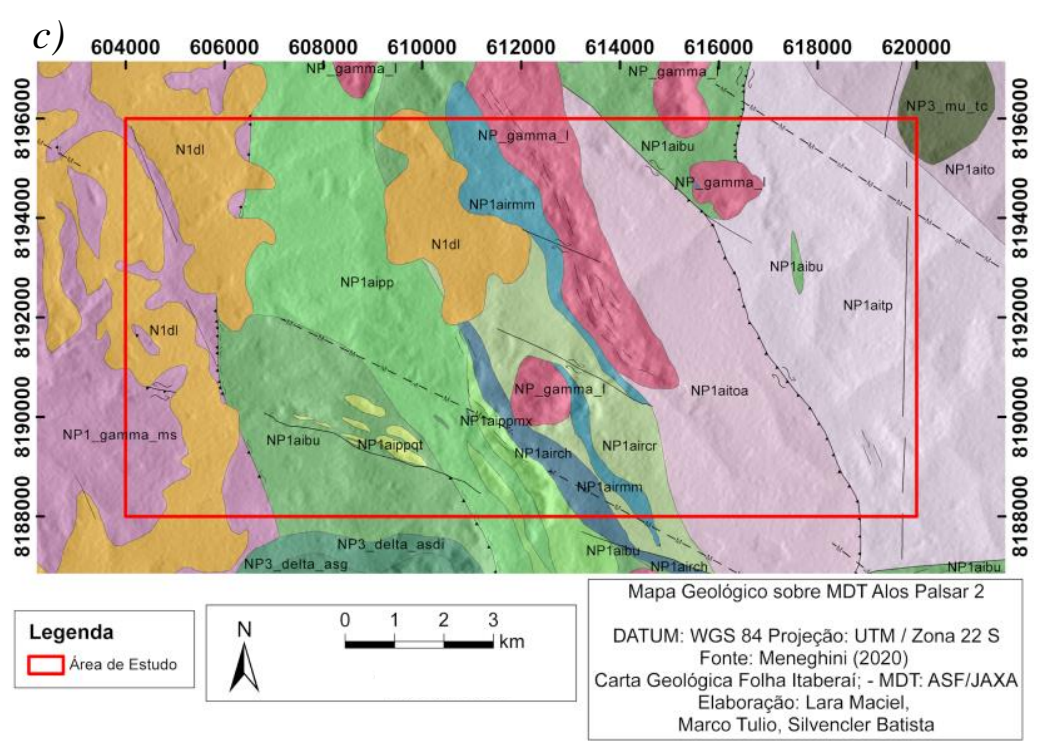

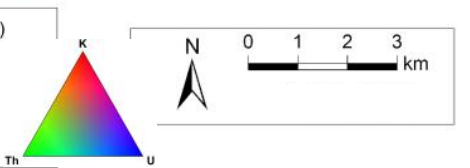

-Mapa de Dominios Gamaespectrométricos sobre MDT

DATUM: WGS 84 Projeçăo: UTM / Zona $22 \mathrm{~S}$ Fonte: Elaboração via Esri ArcGis 10.6 - Geoprossecing Tools: Intersect; MDT JAXA/ASF Alos Palsar 2
Carta Topográfica: SE.22-X-A-III

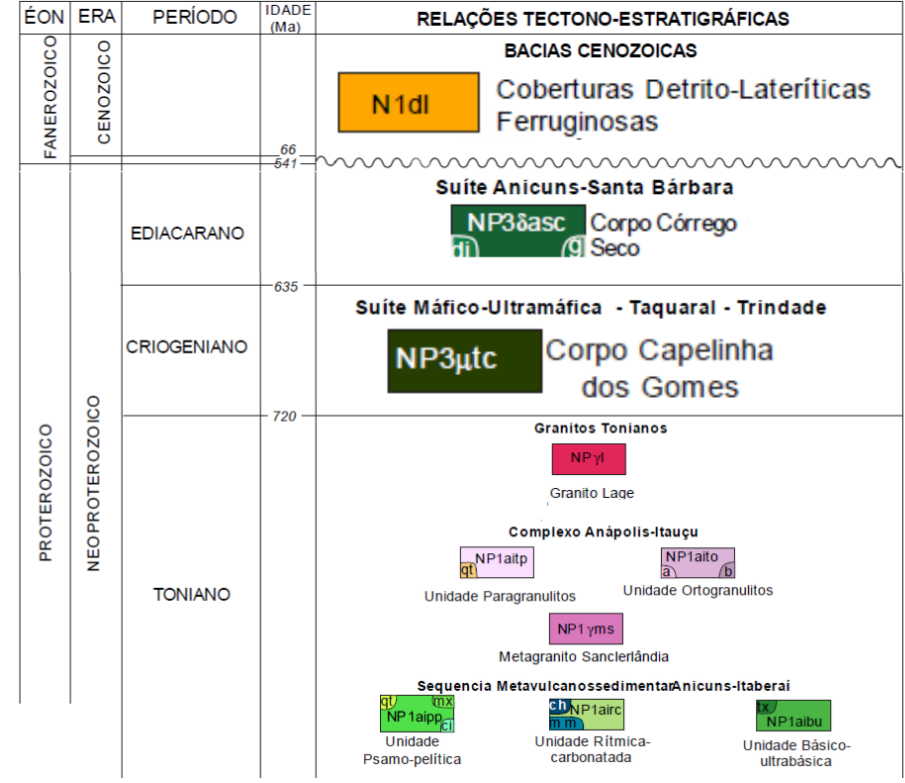

Legenda Interpretação Gamaespectrométrica

- Lineamentos Gamaespectometricos Domínios Gamaespectrométricos I Alto K / Alto Th / Baixo-Médio U II Alto K / Baixo Th / Baixo U III Alto K / Médio Th / Var. U IV Baixo K / Alto Th / Médio-Alto U $V$ Baixo K / Baixo Th / Baixo-Médio U VI Baixo K / Médio Th / Var. U VII Alto Th / Médio K / Médio-Alto U VIII Baixo Th / Médio K / Baixo-Médio U IX Médio Th / Médio K/ Médio-Alto U

\section{Convenções Geológicas}

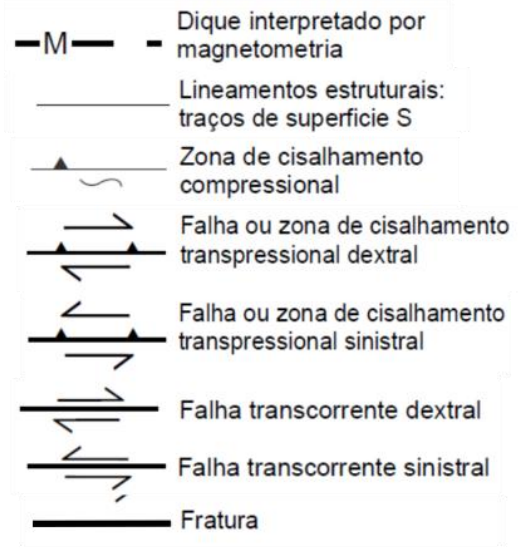

Figura 2 - Recorte da Área de Estudo com (a) Imagem de Gamaespectrometria Ternária RGB, dos canais K Th U. (b) Mapa de domínios Gamaespectrométricos. (c) Mapa Geológico Regional (Meneghini \& Carneiro, 2020). 

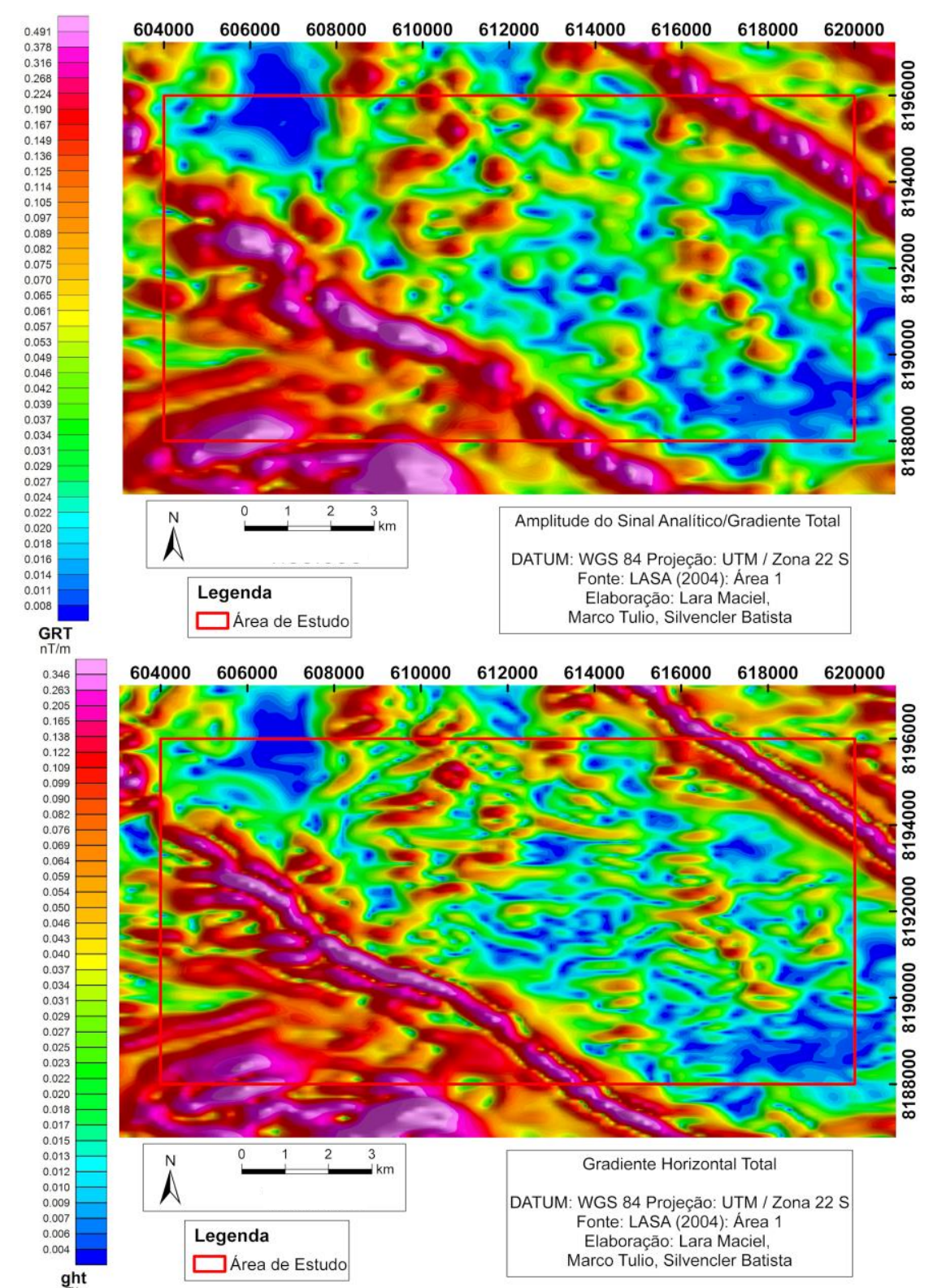
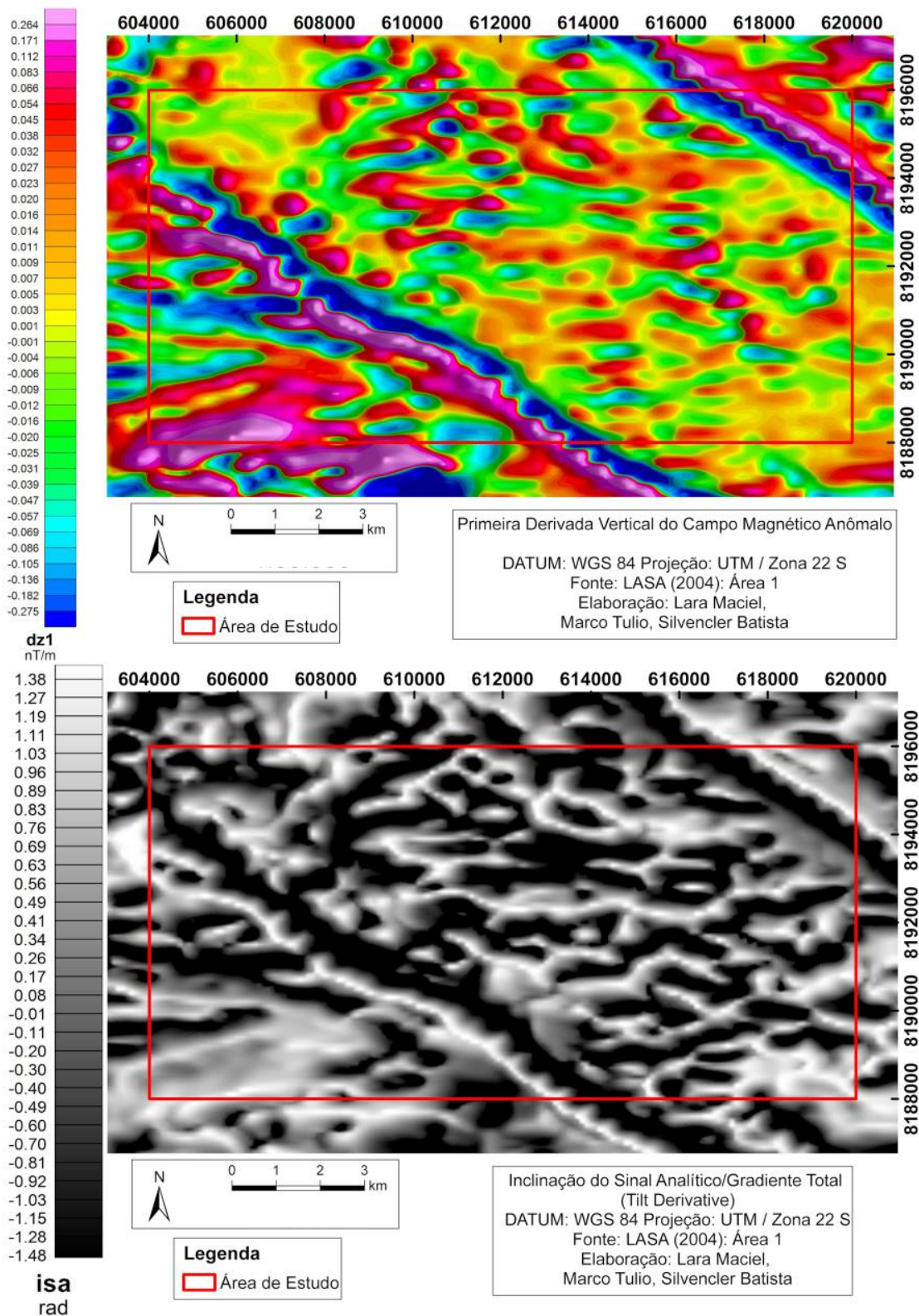

Figura 3 - Mapas Magnéticos do Gradiente Total, Primeira Derivada Vertical, Gradiente Horizontal Total e Inclinação do Sinal Analítico. 